\title{
OCORRÊNCIA PRECOCE DA MOSCA DAS FRUTAS EM AMEIXAS
}

\author{
INCIDENCE OF THE SOUTHAMERICAN FRUIT FLY ON PLUMS
}

- NOTA -

Luiz Antonio Salles ${ }^{1}$

RESUMO

O objetivo deste estudo foi verificar qual o estágio fenológico mais precoce da fruta de ameixeira em que ocorreria o ataque de mosca das frutas Anastrepha fraterculus. Os estudos foram conduzidos em plantas adultas de ameixeira, expondo-se fêmeas grávidas da mosca das frutas, confinadas em gaiolas com frutos protegidos do ataque natural. Cinco cultivares de ameixeira foram estudados (Amarelinha, Pluma 7, Reubennel, Santa Rosa e Wade). Essa praga ataca frutos de qualquer um dos cultivares logo nos primeiros estádios do desenvolvimento, quando os mesmos têm somente cerca de 2 a $3 \mathrm{~cm}$ de diâmetro.

Palavras-chave: mosca da fruta, Anastrepha fraterculus, ameixeira, resistência genética.

\section{SUMMARY}

The incidence of the southamerican fruit fly, Anastrepha fraterculus, on plum cultivars is reported. The objective of this study was to know the earliest fruit phase that fly attack could occur. Fertilized females were confined with fruits in plum trees in an orchard. Five plums cultivars were studied: Amarelinha; Pluma 7; Reubennel; Santa Rosa and Wade. This pest attack fruits during first stages of their development, mainly they have only from 2 to 3 centimeters of diameter.

Key words: fruit fly, Anastrepha fraterculus, plum, genetic resistance.

A mosca das frutas, Anastrepha fraterculus, constitui-se em sério problema para a fruticultura do Rio Grande do Sul há mais de 70 anos. Ao longo deste tempo, essa espécie se adaptou a diversas frutas silvestres e cultivadas, sendo hoje a principal praga da fruticultura no Estado (SALLES, 1995).
A mosca das frutas ataca, praticamente, todas as fruteiras exploradas no Rio Grande do Sul e, na maioria, é a praga principal. Dentre elas, destacam-se a ameixeira, macieira, pereira, goiabeira e pessegueiro. GRELLMANN \& SIMONETTO (1996) apontam a mosca das frutas Anastrepha fraterculus como uma das principais pragas da ameixeira no Rio Grande do Sul.

A incidência e os danos causados pela mosca das frutas está condicionada à presença de frutos e ao seu desenvolvimento, pois essa praga somente ataca os frutos que apresentem determinadas condições. No pêssego, a mosca ataca quando os frutos já estão no período de inchamento (SALLES, 1994) e, na maçã, ataca desde que os frutos tenham cerca de dois centímetros de diâmetro (MAGNABOSCO, 1994). Portanto, o conhecimento do estádio em que o fruto é atacado pela mosca é fator importante e decisivo para a adoção de medidas corretas de controle. GRELLMANN \& SIMONETTO (1995) estudaram a fenologia de vários cultivares de ameixeira e demonstram haver marcantes diferenças no ciclo vegetativo; conseqüentemente, podem-se esperar diferenças quanto ao ataque de pragas, incluindo a mosca das frutas.

De outro lado, freqüentemente chegam à EMBRAPA-CPACT ameixas coletadas de quedas prematuras de frutos. O exame desse material, geralmente, mostra lesões na casca e internas, supostamente, devido ao ataque de moscas das frutas. Este trabalho foi conduzido com o objetivo de elucidar a ocorrência precoce da mosca das frutas em ameixa.

O estudo foi desenvolvido no CPACTEMBRAPA, em Pelotas, RS, em 1996 e 1997, com

\footnotetext{
${ }^{1}$ Engenheiro Agrônomo, PhD, EMBRAPA/Centro de Pesquisa Agropecuária de Clima Temperado, CP 403, 96001-970, Pelotas, RS
} Bolsista do CNPq. 
cinco cultivares de ameixeira (Prunnus salicina): Amarelinha; Pluma 7; Reubennel; Santa Rosa e Wade. Tão logo os frutos estavam formados, procedeu-se o ensacamento de ramos com 6 a 10 frutos, com saco de tecido tipo filó, suportados por uma armação de arame, para evitar o possível ataque natural de mosca das frutas. Nessas gaiolas, colocaram-se 10 moscas das frutas fêmeas já fertilizadas, provenientes de criação de laboratório. Colocaramse cinco conjuntos em cada cultivar para cada época de confinamento. As moscas permaneciam confinadas com os frutos por 48 horas, sendo após, retiradas. Os frutos permaneciam na planta e no interior da gaiola-manga por mais duas semanas, quando eram transferidos para laboratório para análises.

Em 1996, o primeiro confinamento de mosca foi realizado em 8 de novembro, quando os frutos tinham o diâmetro médio de $2,2 \mathrm{~cm}$, na cv.Amarelinha; $2,4 \mathrm{~cm}$, na cv. Pluma $7 ; 2,4 \mathrm{~cm}$, na cv. Santa Rosa; $2,8 \mathrm{~cm}$, na cv. Reubennel e 2,6cm, na cv. Wade. Seguiram-se mais três épocas de confinamento (12, 14 e 18 de novembro). Constatou-se que, no primeiro confinamento ( 8 de novembro), ocorreu ataque aos frutos dos cinco cultivares. Nos demais confinamentos, também ocorreram ataques generalizados.

Em 1997, iniciou-se o confinamento mais cedo, embora os frutos já estivessem com o tamanho aproximado de quando se iniciaram os confinamentos em 1996. Em 97, o primeiro confinamento foi em 24 de outubro, quando os frutos tinham o diâmetro médio de: $2,4 \mathrm{~cm}$, na Amarelinha; $2,2 \mathrm{~cm}$, na Pluma 7; 2,7cm, na Santa Rosa; 2,7cm, na Reubennel e $2,6 \mathrm{~cm}$, na Wade. Seguiram-se mais quatro épocas de confinamento (28, 31 de outubro, 3 e 7 de novembro). Novamente ocorreu ataque em todos os cultivares desde a primeira data de confinamento. Nos dois anos, a frequiência de ataque, expressa pelo numero de puncturas causadas pelas fêmeas para ovipositarem e pela presença de galerias, aumentou nas duas últimas datas de confinamento.

Não se observou o desenvolvimento de larvas nos frutos em qualquer um dos cultivares nos dois anos e em nenhuma data de confinamento. Isso sugere que deve haver um estágio mais avançado do fruto, independente do cultivar, no qual a larva da mosca das frutas encontra condições para se desenvolver. Todavia, o dano inicial, causado pela puncutura da fêmea e pelo início de ataque da larva, que foram caracterizados, deverá ser totalmente irreversível ao longo do desenvolvimento e maturação do fruto, certamente prejudicando o seu desenvolvi- mento, tamanho, formato e, conseqüentemente, o valor comercial, e que acontece em maçãs, por exemplo (MAGNABOSCO, 1994).

O dano causado pela mosca adulta na epiderme e primeiras camadas da polpa do fruto parece acelerar o desenvolvimento e maturação precoce, ocorrendo o amarelecimento dos frutos com cerca de três centímetros de diâmetro. No cultivar Wade, os frutos atacados ficaram com coloração avermelhada, enquanto que os não expostos às moscas permaneceram com a coloração normal (verde-amarelados). Isso ocorreu quando os frutos tinham cerca de 2,8 centímetros de diâmetro, no segundo confinamento.

Muitos frutos caíram dentro da gaiola que permanecia na planta, ao longo das duas semanas (nos cinco cultivares). Isso sugere que a queda de frutos pequenos tenha relação com o ataque da mosca das frutas.

$\mathrm{Na}$ epiderme do fruto, o local da punctura da mosca, ocorreu a cicatrização da lesão do tecido e originou-se um pequeno ponto escurecido, contrastando visivelmente com a epiderme normal, conforme também acontece em maçãs.

As minúsculas e finas galerias causadas pelas larvas ficavam escurecidas e formava "resina" nessas galerias, o que poderia ser um dos fatores de mortalidade das larvas durante os primeiros estádios de desenvolvimento do fruto.

Conclui-se que a mosca das frutas, Anastrepha fraterculus, ataca frutos de qualquer um dos cinco cultivares de ameixeira logo nos primeiros estádios do desenvolvimento, quando os mesmos têm somente cerca de 2 a $3 \mathrm{~cm}$ de diâmetro.

\section{REFERÊNCIAS BIBLIOGRÁFICAS}

GRELLMANN, E.O., SIMONETTO, P.R. Dados de fenologia e produção de cultivares de ameixeira. Porto Alegre: FEPAGRO, 1995. 11 p. Circular Técnica, 3.

GRELLMANN, E.O., SIMONETTO, P.R. A cultura da ameixeira. Porto Alegre: FEPAGRO, 1996. 32 p. Boletim Técnico, 4.

MAGNABOSCO, A.L. Influência de fatores físicos e químicos de maçãs, CV. Gala, no ataque e desenvolvimento larval de Anastrepha fraterculus (Wied., 1830) (Diptera:Tephritidae). Pelotas, RS. 95 p. Tese (Mestrado em Fitossanidade)- Curso de Pós-graduação em Agronomia, Universidade Federal de Pelotas, 1994

SALLES, L.A.B. Período de ataque e de controle da moscadas-frutas em pessegueiro.HortiSul, Pelotas. v. 3 , n. 1, p. 47$51,1994$.

SALLES, L. A. B. Bioecologia e controle da mosca-das-frutas sul-americana. Pelotas: EMBAPA/CPACT, 1995. 58p. 